\title{
Characteristics of Patients in Treatment for Alcohol and Drug Addiction Who Succeed in Changing Smoking, Weight, and Physical Activity: A Secondary Analysis of an RCT on Combined Lifestyle Interventions
}

\author{
Mette Rasmussen ${ }^{a, b}$ Karen Hovhannisyan ${ }^{b}$ Johanna Adami ${ }^{c}$ \\ Hanne Tønnesen ${ }^{a, b}$ \\ aDepartment of Health Sciences, Clinical Health Promotion Centre, WHO-CC, Lund University, Lund, Sweden; \\ ${ }^{b}$ Clinical Health Promotion Centre, WHO-CC, The Parker Institute, University of Copenhagen, Copenhagen, \\ Denmark; 'Sophiahemmet University, Stockholm, Sweden
}

\section{Keywords}

Alcohol addiction - Drug addiction - Lifestyle change .

Smoking cessation - Dietary counselling - Physical activity .

Integrated program · Multi-factorial lifestyle intervention

\begin{abstract}
Introduction: Patients addicted to alcohol or drug often have additional unhealthy lifestyles, adding to the high mortality and morbidity in this patient group. Therefore, it is important to consider lifestyle interventions as part of the usual addiction treatment. Objective: The aim was to identify predictors of successful changes in lifestyle risk factors among patients in treatment for alcohol or drug addiction. Methods: We conducted a secondary analysis of a trial using a 6-week intensive integrated lifestyle intervention: The very integrated program (VIP). Patients were recruited in Addiction Centres Malmö and Psychiatry Skåne, Sweden. The primary outcome was successful changes in lifestyle, measured as quitting tobacco, exercising $30 \mathrm{~min}$ per day, and not being over- or underweight after 6 weeks and 12 months. Results: A total of 212 patients were included in the RCT, and 128 were included in this secondary analysis: 108 at 6 weeks and
\end{abstract}

karger@karger.com www.karger.com/ear

Karger $\stackrel{\text { ' }}{5}$

GOPEN ACCESS
(C) 2020 The Author(s)

Published by S. Karger AG, Basel

This is an Open Access article licensed under the Creative Commons Attribution-NonCommercial-4.0 International License (CC BY-NC) (http://www.karger.com/Services/OpenAccessLicense), applicable to the online version of the article only. Usage and distribution for commercial purposes requires written permission.
89 at 12 months of follow-up. A total of 69 patients were respondents at both follow-ups. The follow-up rates were 51 and $42 \%$, respectively. More education, having at least 2 lifestyle risk factors and having a high quality of life were predictors of a successful change in lifestyle after 6 weeks. After 12 months, the predictors for a successful outcome were having 3 or more risk factors, while an education level up to 3 years was a negative predictor. Conclusions: Having several unhealthy lifestyles in addition to alcohol and drug addiction was a significant predictor of successful lifestyle changes in the short- and long term after the VIP for lifestyle interventions. Likewise, education was significant. The results should be considered in future development and research among this vulnerable group of patients.

(C) 2020 The Author(s)

Published by S. Karger AG, Basel

\section{Introduction}

Patients with alcohol and drug addiction often have other unhealthy lifestyles, such as smoking, weight problems, and physical inactivity, all of which add to the high mortality and morbidity originating from the alcohol and 
drug addiction [1]. Therefore, it is necessary to consider lifestyle interventions as part of the usual addiction treatment and to evaluate comprehensive programs tailored to the different combinations of unhealthy lifestyles among this vulnerable patient group.

There are very few scientific reports evaluating the effect of multifactorial programs targeting several lifestyle factors at the same time. We have recently reported the results from a randomized trial finding no short-term effect on consumption, lifestyle factors, comorbidity symptoms or health-related quality of life (QoL) by a very integrated program (VIP) among patients in treatment for alcohol or drug addiction. At the 1-year follow-up, it seems that the patients in the control group had significantly more total substance-free days than the intervention group [2]. However, the follow-up rate was not impressive, and therefore, imputation of baseline results as follow-up results may have underestimated a possible effect on the patients' lifestyles.

In contrast, some good results have been reported for interventions aimed at only 1 factor. Thus, a 12-month intensive intervention has been reported for smoking cessation among a mixed cohort of patients in treatment for alcohol or drug addiction and psychiatric diseases [3]. Two randomized trials in the general population and among patients with alcohol addiction, respectively, showed not only significant quit rates but also a reduction in drinking habits [4-6]. In contrast, a randomized trial among smokers with psychotic disorders did not show any difference in smoking status and cardiovascular risk between 2 lifestyle interventions [7]. It seems promising to add organizational change interventions, such as a unit for smoking cessation and introduce smoke-free surroundings [8]. Furthermore, the changes in public information and attitudes to smoking over time may also influence the smoking rate among this patient group [9]. Physical exercise as a stand-alone intervention may reduce the consumption of alcohol among hazardous drinkers $[6,10]$. This is also being evaluated in a sizeable ongoing randomized trial [11]. A qualitative study identifies that an important motivation source for a physical active lifestyle among persons with alcohol use disorder seems to come from the obtainable benefits [12]. This information is an integrated part of the VIP. Few studies have been conducted on food interventions, but a review including a broad variety of study designs and qualities indicates that handing out food products to homeless problem drinkers seems to be effective [13]. Overall, an effect of mono-factor interventions and not the comprehensive VIP may add to some existing general experienc- es of taking 1 step at a time. The aim of this secondary analysis of the VIP data was to identify predictors of successful changes in lifestyle risk factors such as smoking, overweight, underweight, and physical inactivity among patients in treatment for addiction to alcohol or drugs.

\section{Methods}

Data Source and Permissions

This study was based on data from a parallel randomized single-blind controlled trial on combined lifestyle interventions among patients with alcohol and/or drug addiction. The randomized controlled trial (RCT) was conducted in Region Skåne, Sweden, with patient inclusion from 2011 to 2013 (trial registration number: NCT01414907). All patients gave written informed consent ahead of inclusion. The study intervention called the VIP was compared to treatment as usual [2].

The main results of the RCT showed no differences between the groups regarding time to relapse, treatment adherence, change in lifestyle, quality of life (QoL), or symptoms of comorbidities. However, the intervention group had significantly fewer total substance-free days compared to the control group after 12 months (median [range]: 139 [0-365] vs. 265 [0-366]; $p=0.021$ ) [2]. The RCT was approved by the Central Ethical Review Board (Dnr 2010/470) as well as by the Swedish Data Protection Authority. This study did not require further permission.

Design

This was a secondary analysis of the VIP study. Patients were recruited at 4 units at Addiction Centre Malmö and 1 unit at Integrated Community Care, Psychiatry Skåne, Sweden. In the intervention arm, patients participated in the VIP, which lasted 6 weeks after randomization. The control group received treatment as usual. Although patients were randomized at 5 different units, the lifestyle interventions were conducted at 1 site. The recruiting procedure and the VIP have been described in detail elsewhere $[1,2]$.

\section{Participants}

A total of 322 patients over the age of 18 years were assessed for eligibility, and 212 patients fulfilled the study criteria and were included in the RCT [2]. The inclusion criteria were having at least 1 lifestyle risk factor (smoking/snuffing, physical inactivity, overweight, or underweight) and having at least 1 comorbidity (heart disease, lung disease, liver disease, or diabetes).

In this study, we examined the characteristics of the patients who were successful in changing at least 1 lifestyle risk factor after 6 weeks and 12 months, respectively, against those who did not manage to improve their lifestyles. Therefore, patients who did not respond to follow-up were excluded from the analyses. At the 6-week follow-up, 108 patients were respondents, and this was the case for 89 patients at the 12 -month follow-up, corresponding to follow-up rates of 51 and $42 \%$, respectively.

\section{Intervention and Outcome Measures}

The intervention group received the VIP as an addition to their usual addiction treatment. VIP was a tailored intensive educational program lasting 6 weeks. It included weekly patient education, pharmaceutical support, participation in a workshop for chronic medical 
Table 1. Baseline characteristics for the alcohol- and drug-addicted patients in the secondary analyses at followup of 6 weeks and 12 months after inclusion in the randomized trial of the very integrated lifestyle intervention program (VIP)

\begin{tabular}{|c|c|c|}
\hline & \multicolumn{2}{|l|}{ Baseline } \\
\hline & $\begin{array}{l}\text { 6-week follow-up } \\
n(\%)\end{array}$ & $\begin{array}{l}\text { 12-month follow-up } \\
n(\%)\end{array}$ \\
\hline Total & $108(100)$ & $89(100)$ \\
\hline \multicolumn{3}{|l|}{ Drug or alcohol treatment } \\
\hline Alcohol & $68(63.0)$ & $60(67.4)$ \\
\hline Drug & $39(36.1)$ & $29(32.6)$ \\
\hline \multicolumn{3}{|l|}{ Trial arm } \\
\hline Intervention & $47(43.5)$ & $42(47.2)$ \\
\hline Control & $61(56.5)$ & $47(52.8)$ \\
\hline \multicolumn{3}{|l|}{ Participants } \\
\hline \multicolumn{3}{|l|}{ Sex } \\
\hline Men & $71(65.7)$ & $58(65.2)$ \\
\hline Women & $37(34.3)$ & $31(34.8)$ \\
\hline Age (median/range), years & $54(26-77)$ & $55(28-77)$ \\
\hline$<34$ & $4(3.7)$ & $2(2.3)$ \\
\hline $35-44$ & $15(13.9)$ & $12(13.5)$ \\
\hline $45-54$ & $41(38.0)$ & $29(32.6)$ \\
\hline $55-64$ & $34(31.5)$ & $34(38.2)$ \\
\hline$>65$ & $14(31.0)$ & $12(13.5)$ \\
\hline \multicolumn{3}{|l|}{ Education } \\
\hline No or short education & $20(18.5)$ & $20(22.5)$ \\
\hline Up to 3 years & $71(65.7)$ & $54(60.7)$ \\
\hline 3 years or more & $16(14.8)$ & $15(16.9)$ \\
\hline \multicolumn{3}{|l|}{ Lifestyle factors } \\
\hline Smoking/snuff ${ }^{\mathrm{a}}$ & $82(75.9)$ & $67(75.3)$ \\
\hline CO Measurements (median/range) & $13(1-48)$ & $12(1-48)$ \\
\hline Underweight $^{\mathrm{b}}$ & $9(8.3)$ & $7(7.9)$ \\
\hline Overweight ${ }^{\mathrm{c}}$ & $86(79.6)$ & $70(78.7)$ \\
\hline BMI (median/range) & $28(19-43)$ & $28(19-43)$ \\
\hline Waist measurement (median/range) & $99(69-143)$ & $99(70-143)$ \\
\hline Physical inactivity & $33(30.6)$ & $25(28.1)$ \\
\hline \multicolumn{3}{|l|}{ Comorbidity } \\
\hline Lung disease & $46(42.6)$ & $33(37.1)$ \\
\hline MRC breathlessness scale (median/range) & $2(1-5)$ & $2(1-5)$ \\
\hline Heart disease & $62(57.4)$ & $55(61.8)$ \\
\hline NYHA scale (median/range) & $1(1-5)$ & $1(1-5)$ \\
\hline Diabetes & $15(13.9)$ & $10(11.2)$ \\
\hline Liver disease & $37(34.2)$ & $31(34.8)$ \\
\hline Other comorbidity & $35(32.4)$ & $29(32.6)$ \\
\hline \multicolumn{3}{|l|}{ QoL (SF-36) } \\
\hline SF-36 (median/range) & $51(2-95)$ & $52(2-93)$ \\
\hline SF-36 physical health (median/range) & $58(1-100)$ & $59(1-98)$ \\
\hline SF-36 mental health (median/range) & $45(0-94)$ & $47(0-94)$ \\
\hline
\end{tabular}

VIP, very integrated program; QoL, quality of life; SF-36, Short Form 36 Health Assessment. ${ }^{a}$ Daily smoking and/or daily snuffing. ${ }^{\mathrm{b}} \mathrm{BMI}<20.5 .{ }^{\mathrm{c}} \mathrm{BMI}>25.5$ or waist measure $>80 \mathrm{~cm}$ for women $/>94 \mathrm{~cm}$ for men.

diseases, and motivational interviewing. In concordance with the lifestyle of the patient, the intervention targeted tobacco cessation, physical activity, and avoiding over- and underweight. The control group received the usual treatment for addiction and were free to use the local interventions aimed at improving lifestyles.
The main outcome measures were substance-free days, time to relapse, and treatment adherence, which were assessed after 6 weeks and 12 months. Secondary outcomes were lifestyle factors, comorbidities, and QoL. 
Table 2. Prevalence of lifestyle risk factors at baseline and at follow-up for the patients attending the 6-week and the 12-month follow-up, respectively

\begin{tabular}{lcccc}
\hline & $\begin{array}{l}\text { Baseline } \\
n=108\end{array}$ & 6 weeks & $\begin{array}{l}\text { Baseline } \\
n=89\end{array}$ & 12 months \\
\hline Smoking/snuffing (daily), $n(\%)$ & $82(75.9)$ & $70(64.8)$ & $67(75.3)$ & $62(69.7)$ \\
Physical inactivity, $n(\%)$ & $33(30.6)$ & $30(27.8)$ & $25(28.1)$ & $28(31.4)$ \\
Underweight, $n(\%)$ & $9(8.3)$ & $8(7.4)$ & $7(7.9)$ & $4(4.5)$ \\
Overweight, $n(\%)$ & $86(79.6)$ & $72(66.7)$ & $70(78.7)$ & $66(74.2)$ \\
Still at least 1 risk factor, $n(\%)$ & $108(100)$ & $101(93.5)$ & $89(100)$ & $84(94.4)$ \\
\hline
\end{tabular}

\section{Variables}

\section{Risk Factors}

The 4 risk factors were smoking (daily smoking or daily use of snuff), physical inactivity (being physical active $<30 \mathrm{~min}$ per day), overweight (BMI $>25.5$ or waist measure $>80 \mathrm{~cm}$ for women/ $>94$ $\mathrm{cm}$ for men), or underweight (BMI <20.5).

\section{Comorbidities}

The comorbidities were chronic health conditions requiring treatment: lung disease, heart disease, liver disease, or diabetes.

Other Variables

A number of prognostic variables were collected in the RCT and used in this study. These included sex, age, trial arm, level of education, QoL, whether the patient was primarily being treated for alcohol or drug addiction, and substance-free days. Age was treated as a continuous variable. All other variables were collected as categorical variables or collected and then categorized. QoL was assessed using the Short Form 36 Health Assessment [14], and the results were dichotomized using the median as the cutoff value to create a top 50\%. Likewise, substance-free days were dichotomized, creating a top $10 \%$ using the 90th percentile as a cutoff value. The level of education was categorized into 3 groups: no or little education, up to 3 years, or 3 years or more.

\section{Analysis}

Predictors of a successful change in risk factor(s) were identified, and odds ratios and 95\% confidence intervals were estimated using logistic regression analyses. Initially, univariate analyses were conducted to test the associations between a successful change in lifestyle and trial arm, age, sex, alcohol or drug treatment, number of comorbidities, substance-free days, QoL, level of education, and number of risk factors at baseline. Age was entered as a continuous variable, while all other variables were entered as categorical variables. Then, all variables were entered into the multivariable logistic regression model, and the final model was fitted based on the initial analyses. The final model was adjusted for QoL, the number of risk factors, and level of education. Patients with missing data were excluded from the analysis. In the final analyses, a 2 -sided $p$ value $<0.05$ was considered statistically significant. All analyses were conducted using STATA.IC 15.

\section{Ethical Considerations}

All patients in the VIP study were informed about the physical examinations and the procedure of the data collection before written informed consent was given. Only the patients who gave informed consent participated in the study. Participants could withdraw their consent at any time without explanation or consequences for the usual treatment and care [2].

\section{Results}

\section{Baseline Characteristics of Those in the Analyses}

In total, 128 patients who attended the 6-week and/or 12-month follow-up supplied data for this study; 108 patients attended the 6 -week follow-up, and 89 attended the 12-month follow-up. In total, 69 patients attended both the 6-week and 12-month follow-ups. Baseline characteristics for the patients are shown in Table 1.

Dropout analysis conducted in the RCT [2] showed that the respondents in the original study were less likely to be overweight (73 vs. $86 \%, p=0.046)$ and physically inactive (32 vs. $47 \%, p=0.042$ ). Furthermore, they had a higher self-reported QoL score for the physical factors measured by the Short Form 36 Health Assessment (median: 59 vs. $51 \%, p=0.042$ ).

\section{Results after 6 weeks and 12 months}

Table 2 shows the numbers and proportions of participants with the 4 lifestyle risk factors. Though not statistically significant, the prevalence of all risk factors, except for physical inactivity after 12 months, decreased from baseline to follow-up.

At the end of the 6-week integrated program and after 12 months, the only predictor showing a significant difference in the univariate analyses was having at least 3 risk factors after 6 weeks (Table 3). The multivariable models, displayed in Table 4, showed that being in the QoL top 50\%, having a high level of education, and having at least 2 unhealthy lifestyles (in addition to the alcohol and drug addiction) were predictors of a successful outcome.

\section{Discussion}

In this secondary analysis of 128 patients, having several lifestyle risk factors in addition to alcohol or drug addiction was a predictor of a successful lifestyle change after both 6 weeks and 12 months. More education and 
Table 3. Univariate analyses testing the difference in prognostic factors between participants who were successful in changing lifestyle risk factors and those who were not

\begin{tabular}{|c|c|c|c|c|c|c|c|c|}
\hline & \multicolumn{4}{|c|}{6 weeks } & \multicolumn{4}{|c|}{12 months } \\
\hline & OR & \multicolumn{2}{|c|}{$95 \%$ CI } & $p$ value & OR & \multicolumn{2}{|c|}{$95 \% \mathrm{CI}$} & $p$ value \\
\hline \multicolumn{9}{|l|}{ Trial arm } \\
\hline Intervention & 1 & & & & 1 & & & \\
\hline Control & 1.01 & 0.46 & 2.25 & 0.97 & 1.32 & 0.46 & 3.82 & 0.51 \\
\hline Age (continuous) & 1.01 & 0.97 & 1.06 & 0.49 & 0.98 & 0.92 & 1.04 & 0.46 \\
\hline \multicolumn{9}{|l|}{ Sex } \\
\hline Men & 1 & & & & 1 & & & \\
\hline Women & 1.44 & 0.63 & 3.30 & 0.39 & 0.87 & 0.29 & 0.23 & 0.80 \\
\hline \multicolumn{9}{|l|}{ Treatment } \\
\hline Alcohol & 1 & & & & 1 & & & \\
\hline Drug & 0.75 & 0.33 & 1.72 & 0.50 & 0.65 & 0.20 & 2.10 & 0.47 \\
\hline \multicolumn{9}{|l|}{ Substance-free days } \\
\hline Not top $10 \%$ & 1 & & & & 1 & & & \\
\hline Top 10\% & 0.77 & 0.28 & 2.13 & 0.62 & 0.81 & 0.14 & 4.84 & 0.82 \\
\hline \multicolumn{9}{|l|}{ Comorbidity } \\
\hline 1 comorbidity & 1 & & & & 1 & & & \\
\hline 2 comorbidities & 1.35 & 0.56 & 3.24 & 0.51 & 2.08 & 0.61 & 7.13 & 0.24 \\
\hline 3 comorbidities & 1.08 & 0.31 & 3.75 & 0.91 & 4.17 & 0.91 & 19.2 & 0.07 \\
\hline 4 comorbidities & 0.65 & 0.06 & 6.72 & 0.71 & & & & \\
\hline 5 comorbidities & & & & & & & & \\
\hline \multicolumn{9}{|l|}{ QoL } \\
\hline Not top $50 \%$ & 1 & & & & 1 & & & \\
\hline Top $50 \%$ & 1.62 & 0.73 & 3.61 & 0.24 & 0.59 & 0.20 & 1.70 & 0.33 \\
\hline \multicolumn{9}{|l|}{ Education level } \\
\hline No or short education & 1 & & & & 1 & & & \\
\hline Up to 3 years & 1.12 & 0.38 & 3.30 & 0.84 & 0.63 & 0.19 & 2.13 & 0.46 \\
\hline 3 years or more & 3.89 & 0.97 & 15.7 & 0.06 & 0.21 & 0.02 & 2.22 & 0.20 \\
\hline \multicolumn{9}{|l|}{ Risk factors } \\
\hline 1 risk factor & 1 & & & & 1 & & & \\
\hline 2 risk factors & 2.97 & 0.89 & 9.94 & 0.08 & 2.96 & 0.31 & 28.6 & 0.35 \\
\hline 3 risk factors & 24.7 & 5.84 & 104.4 & $\leq 0.01^{*}$ & & & & \\
\hline
\end{tabular}

OR, odds ratio; CI, confidence interval; QoL, quality of life. * Indicates a $p$ value $<0.05$.

Table 4. Multivariable logistic regression analyses comparing patients who successfully changed at least 1 lifestyle factor compared to patients who did not

\begin{tabular}{|c|c|c|c|c|c|c|c|c|}
\hline & \multicolumn{4}{|c|}{6 weeks } & \multicolumn{4}{|c|}{12 months } \\
\hline & OR & \multicolumn{2}{|c|}{$95 \% \mathrm{CI}$} & $p$ value & OR & \multicolumn{2}{|l|}{$95 \% \mathrm{CI}$} & $p$ value \\
\hline \multicolumn{9}{|l|}{ QoL } \\
\hline Not top $50 \%$ & 1 & & & & 1 & & & \\
\hline Top 50\% & 3.99 & 1.18 & 13.4 & $0.026^{*}$ & 3.05 & 0.54 & 17.1 & 0.206 \\
\hline \multicolumn{9}{|l|}{ Education level } \\
\hline No or short education & 1 & & & & 1 & & & \\
\hline Up to 3 years & 1.58 & 0.38 & 6.57 & 0.532 & 0.16 & 0.03 & 0.87 & $0.034^{*}$ \\
\hline 3 years or more & 22.0 & 3.02 & 160.2 & $0.002^{*}$ & 0.27 & 0.02 & 2.96 & 0.284 \\
\hline \multicolumn{9}{|l|}{ Risk factors } \\
\hline 1 risk factor & 1 & & & & 1 & & & \\
\hline 2 risk factors & 5.97 & 1.27 & 28.1 & $0.024^{*}$ & 4.67 & 0.50 & 43.9 & 0.178 \\
\hline 3 risk factors & 108.7 & 14.4 & 821.5 & $\leq 0.001^{*}$ & 849.7 & 34.8 & $20,748.7$ & $\leq 0.001^{*}$ \\
\hline
\end{tabular}

OR, odds ratio; CI, confidence interval QoL, quality of life. ${ }^{*}$ Indicates a $p$ value $<0.05$. 
QoL were predictors in the short term only, while having an education up to 3 years was a negative predictor in the long term.

A high QoL, more education, and having at least 2 lifestyle risk factors were predictors of a successful change in lifestyle after 6 weeks. After 12 months, the predictor for a successful outcome was having 3 or more risk factors.

The most surprising result was that having several unhealthy lifestyle factors at inclusion in the VIP study was associated with a successful change in lifestyle in both the short- and long term. This has not been reported before and may contradict the general experience that taking 1 step at a time is better than trying to change all aspects at the same time. The result could be due to the VIP itself, as it has been developed to target more lifestyles simultaneously. It could also be explained by especially high expectations of a study effect from the participants with the most risky lifestyles, encouragement by the staff, and enthusiasm by the project group. If this predictor could be found in future randomized studies of comprehensive integrated lifestyle interventions, it may be promising for those groups suffering from many coexisting unhealthy lifestyles. It may even work against the inequity in health, as clustering of unhealthy lifestyles also has a clear social gradient [15]. In the short term, we found that longer education (3 years or more) was a significant predictor of changing lifestyles among this group of vulnerable patients - and maybe especially the VIP that comprehends direct education, which could be more familiar for the persons with longer education. It is, however, not surprising, as significant associations have been established among other groups undertaking lifestyle interventions or other treatments [16-19]. Attempts have been made to design a special program to attract smokers with little or no education but no successful change in recruitment has yet occurred [20]. The negative predictive value of a longer education up to 3 years on long term lifestyle change is more surprising. It could be speculated that a longer education is not so beneficial after the intervention period finishes and/or it does not help prevent relapses. If this is the case, a possibility would then be to introduce brush-up sessions regularly after the end of the 6-week VIP. Another explanation of the results may be that a combination of other factors develops an increase in impact over time, such as sex and age or confounders not measured in this study. However, it could also be a local Swedish phenomenon, as education in Sweden is usually of longer duration [21]. Additionally, health-related QoL was a predictor of short-term lifestyle changes, and this impact on successful outcomes after intervention has been described previously [22].

It was disappointing that the intervention itself was not a predictor of changing lifestyles. Other authors have reported minimal or no effect of lifestyle interventions among other vulnerable groups of patients, such as patients with severe mental illness $[23,24]$. Thus, a recent review on weight management identified a minor statistical effect, but without clinical relevance [23]. The comprehensive lifestyle intervention program CHANGE found no effect at any of 2 different intervention points compared to a control group [24]. Nevertheless, an effect on other important outcomes such as the use of health care services cannot be excluded. Future studies should include evaluation of the use of expensive services in hospitals and emergency settings as well as the services delivered by primary health care, as the first has been reported very high in a study on risky drinking [25].

In contrast, recent studies on only 1 lifestyle factor, especially smoking, have shown effects among patients with alcohol and drug addiction, but here, the interventions seem to be longer, reaching up to 12 months for smoking [3]. Another important element could be handling out healthy food products [13]. The VIP study did not include similar interventions.

\section{Bias and Limitations}

This study may suffer from several biases and limitations. First, this study evaluated associations and not causalities. Second, this analysis of the VIP data may introduce a systematic bias due to the missing data at follow-up and thereby overestimate the importance of predictors of change. The loss to follow-up was $40 \%$, which is unfortunately not uncommon for this group of patients $[26,27]$. However, the importance of education and having several risk factors to be targeted in the tailored VIP intervention was consistent in both the shortand long term, even though the patients followed up at those times were not the exact same individuals. The follow-up rates for lifestyle changes were $51 \%$ after 6 weeks and $42 \%$ after 12 months in the original RCT, which also challenge the reliability of the results in the present study. The generalizability may be limited because the study was performed in a specific setting in the southern part of Sweden. On the other hand, the inclusion of both men and women may be considered a strength.

For the time being, smoke-free psychiatry is being implemented by national or local regulations in several countries to protect against second-hand smoking and 
to support smoking cessation intervention. This has been followed by dramatic changes, doubling the delivered smoking cessation interventions and halving the frequency of smoking $[28,29]$, although this was not the case during the study period in Sweden. The predictors may be different in health-promoting surroundings, and a recent review concluded that organizational changes may also increase smoking cessation intervention and smoking prevalence in alcohol and other drug treatment settings [8].

The clinical impact of the prediction is to focus on lifestyle intervention even among patients with many simultaneous unhealthy lifestyle factors. Another impact is to be aware of the importance of long and short education for the outcome on short- and long term, respectively, in this patient group.

Future research should include the development and evaluation of new and even longer integrated programs, as this group of patients has a very high level of need for effective lifestyle interventions [1]. The intervention program should aim to be beneficial for patients with no or little education.

\section{Conclusion}

Having several unhealthy lifestyles in addition to alcohol and drug addiction was a significant predictor of successful changes in lifestyle in the short- and long term after participating in the VIP study. Likewise, more education and high QoL were significant in the short term. The results should be considered in future development and research among this vulnerable group of patients.

\section{Acknowledgements}

We would like to thank the independent Study Monitor Kerstin Thornqvist and the administrators Cecilia Gravin, Eva Skagert, and Rie Raffing for their great help regarding the identification of the data necessary for this secondary analysis.

\section{Statement of Ethics}

The current study is based on the VIP study which is an RCT with the trial registration number NCT01414907 at clinicaltrials. gov. The RCT was approved by the Central Ethical Review Board (Dnr 2010/470) as well as by the Swedish Data Protection Authority. All patients gave written informed consent before inclusion. This study did not require further permissions.

\section{Conflict of Interest Statement}

The authors have no conflicts of interest to declare.

\section{Funding Sources}

The VIP study has been funded by the Swedish Council for Working Life and Social Research, The Swedish Council for Information on Alcohol and Other Drugs, and Lund University, Sweden.

\section{Author Contributions}

M.R., K.H., J.A., and H.T. contributed to the conception and design. K.H. contributed to the collection of data. M.R. performed the analysis of the data, and H.T., K.H., and J.A. contributed to it. All authors contributed to the interpretation of data. M.R. drafted the manuscript, and H.T., K.H., and J.A. edited it. All authors gave final approval of the manuscript.

\section{References}

1 Hovhannisyan K, Adami J, Wikström MM, Tønnesen H. Very Integrated Program (VIP): smoking and other lifestyles, co-morbidity and quality of life in patients undertaking treatment for alcohol and drug addiction in Sweden. clinhp. 2018;8(1):14-9.

2 Hovhannisyan K, Rasmussen M, Adami J, Wikström M, Tønnesen H. Evaluation of very integrated program: health promotion for patients with alcohol and drug addiction: a randomized trial. Alcohol Clin Exp Res. 2020; 44(7): 1456-67. http://dx.doi.org/10.1111/ acer. 14364

3 Raich A, Pinet C, Ballbè M, Mondon S, Tejedor R, Arnau A, et al. Multimodal treatment for smoking cessation with vareniclinein alcoholic, methadone-maintained, and psy- chotic patients: a one-year follow-up. Tob Induc Dis. 2018 Dec 11;16:58. https://dx.doi. org/10.18332/tid/99541.

4 Toft U, Pisinger C, Aadahl M, Lau C, Linneberg A, Ladelund S, et al. The impact of a population-based multi-factorial lifestyle intervention on alcohol intake. The Inter99 study. Prev Med. 2009;49(2-3):115-21. https:// dx.doi.org/10.1016/j.ypmed.2009.06.007.

5 Pisinger C, Vestbo J, Borch-Johnsen K, Jørgensen T. Smoking cessation intervention in a large randomised population-based study. The Inter99 study. Prev Med. 2005 Mar;40(3): 285-92.

6 O’Malley SS, Zweben A, Fucito LM, Wu R, Piepmeier ME, Ockert DM, et al. Effect of varenicline combined with medical manage- ment on alcohol use disorder with comorbid cigarette smoking: a randomized clinical trial. JAMA Psychiatry. 2018 Feb;75(2):129-38. https://dx.doi.org/10.1001/jamapsychiatry. 2017.3544.

7 Baker AL, Richmond R, Kay-Lambkin FJ, Filia SL, Castle D, Williams JM, et al. Randomized controlled trial of a healthy lifestyle intervention among smokers with psychotic disorders. Nicotine Tob Res. 2015;17(8):946-54.

8 Skelton E, Tzelepis F, Shakeshaft A, Guillaumier A, McCrabb S, Bonevski B. Integrating smoking cessation care in alcohol and other drug treatment settings using an organizational change intervention: a systematic review. Addiction. 2018 Dec;113(12):215872. 
9 Kelly JF, Greene MC, Bergman B, Hoeppner B. Smoking cessation in the context of recovery from drug and alcohol problems: prevalence, predictors, and cohort effects in a national U.S. Sample. Drug Alcohol Depend. 2019 Feb;195:6-12.

10 Jensen K, Nielsen C, Ekstrøm CT, Roessler KK. Physical exercise in the treatment of alcohol use disorder (AUD) patients affects their drinking habits: a randomized controlled trial. Scand J Public Health. 2019 Jun;47(4):4628.

11 Hallgren M, Andersson V, Ekblom Ö, Andréasson S. Physical activity as treatment for alcohol use disorders (FitForChange): study protocol for a randomized controlled trial. Trials. 2018 Feb;19(1):106.

12 Vancampfort D, Van Damme T, Probst M, Vandael H, Hallgren M, Mutamba BB, et al. Motives for physical activity in the adoption and maintenance of physical activity in men with alcohol use disorders. Psychiatry Res. 2018 Mar;261:522-6.

13 Ijaz S, Thorley H, Porter K, Fleming C, Jones $\mathrm{T}$, Kesten J, et al. Interventions for preventing or treating malnutrition in homeless problem-drinkers: a systematic review. Int J Equity Health. 2018 Jan;17(1):8.

14 Ware JE, Kosinski M, Keller S. SF-36 physical and mental health summary scales: a user's manual. Boston, MA: The Health Institute; 1994.

15 Meader N, King K, Moe-Byrne T, Wright K, Graham H, Petticrew M, et al. A systematic review on the clustering and co-occurrence of multiple risk behaviours. BMC Public Health. 2016 Jul;16(1):657.

16 Zhuang YL, Gamst AC, Cummins SE, Wolfson T, Zhu SH. Comparison of smoking ces- sation between education groups: findings from 2 US national surveys over 2 decades. Am J Public Health. 2015 Feb;105(2):373-9.

17 Stegberg M, Hasselgren M, Montgomery S, Lisspers K, Ställberg B, Janson C, et al. Changes in smoking prevalence and cessation support, and factors associated with successful smoking cessation in Swedish patients with asthma and COPD. Eur Clin Respir J. 2018 Jan;5(1):1421389.

18 Blomster JI, Zoungas S, Woodward M, Neal B, Harrap S, Poulter N, et al. The impact of level of education on vascular events and mortality in patients with type 2 diabetes mellitus: results from the ADVANCE study. Diabetes Res Clin Pract. 2017 May;127:212-7.

19 Cafagna G, Seghieri C. Educational level and 30-day outcomes after hospitalization for acute myocardial infarction in Italy. BMC Health Serv Res. 2017 Jan;17(1):18.

20 Rasmussen M, Kaas M, Helldén SM, Kjaer NT, Tønnesen H. Come \& quit: a new flexible, intensive smoking cessation intervention programme. Clin Health Promot. 2019;9(1): 15-23. http://dx.doi.org/10.29102/clinhp. 19004.

21 Statistikdatabasen. Befolkning 16-74 år efter region, utbildningsnivå, ålder och kön. År 1985 - 2018 [Internet] [cited 2020 Mar 31]. Available from: https://www.statistikdatabasen.scb.se/pxweb/sv/ssd/START__UF__ UF0506/Utbildning/.

22 Köhler S, Unger T, Hoffmann S, Mackert A, Ross B, Fydrich T. The relationship of healthrelated quality of life and treatment outcome during inpatient treatment of depression. Qual Life Res. 2015 Mar;24(3):641-9.

23 Speyer H, Jakobsen AS, Westergaard C, Nørgaard $\mathrm{HCB}$, Jørgensen $\mathrm{KB}$, Pisinger $\mathrm{C}$, et al.
Lifestyle interventions for weight management in people with serious mental illness: a systematic review with meta-analysis, trial sequential analysis, and meta-regression analysis exploring the mediators and moderators of treatment effects. Psychother Psychosom. 2019 Nov;88(6):350-62.

24 Jakobsen AS, Speyer H, Nørgaard HCB, Karlsen M, Birk M, Hjorthøj C, et al. Effect of lifestyle coaching versus care coordination versus treatment as usual in people with severe mental illness and overweight: two-years follow-up of the randomized CHANGE trial. PLoS One. 2017 Oct;12(10):e0185881.

25 Miquel L, Manthey J, Rehm J, Vela E, Bustins M, Segura L, et al. Risky alcohol use: the impact on health service use. Eur Addict Res. 2018;24(5):234-44.

26 McHugh RK, Murray HW, Hearon BA, Pratt EM, Pollack MH, Safren SA, et al. Predictors of dropout from psychosocial treatment in opioid-dependent outpatients. Am J Addict. 2013 Jan;22(1):18-22.

27 Graff FS, Griffin ML, Weiss RD. Predictors of dropout from group therapy among patients with bipolar and substance use disorders. Drug Alcohol Depend. 2008 Apr;94(1-3):272-5.

28 Huddlestone L, Sohal H, Paul C, Ratschen E. Complete smokefree policies in mental health inpatient settings: results from a mixed-methods evaluation before and after implementing national guidance. BMC Health Serv Res. 2018 Jul;18(1):542.

29 Gubner NR, Williams DD, Le T, Garcia W, Vijayaraghavan M, Guydish J. Smoking related outcomes before and after implementation of tobacco-free grounds in residential substance use disorder treatment programs. Drug Alcohol Depend. 2019 Apr;197:8-14. 